\title{
Methodology of the Differential Games Simulation in the Studies of the Social Partnership Models in the Continuing Professional Education System
}

\author{
Oksana Avedikovna Nor-Arevian ${ }^{1}$ \\ Larisa Viktorovna Tarasenko 1 \\ Vladimir Alexandrovich Kirik ${ }^{1}$ \\ Tatiana Dmitrievna Skudnova² \\ 1 Southern Federal University, Rostov-on-Don, Russian Federation \\ ${ }^{2}$ Chekhov Taganrog Institute of the Branch of the Rostov State Economic University, Taganrog, Russian Federation \\ Correspondence Email: tis_monti@mail.ru
}

Doi:10.5901/mjss.2015.v6n4s4p237

\begin{abstract}
The article describes the opportunities of the inter-disciplinary methodology for differential games simulation in the studies of the social partnership models in the continuing professional education system. The advantages of the differential games' mathematical apparatus, which allows to perform a qualitative comparative analysis of the efficiency of various models of the social partnership organization (isolation, hierarchy, cooperation), to account the necessity of private and public interests coordination, and to study the dynamic stability of the social partnership relations, are analyzed based on the materials of an empirical research. A technique of mathematical models identification using the opinion polls data and the scenario approach towards differential games solution based on computer simulation are discussed.
\end{abstract}

Keywords: continuous professional education, inter-disciplinary methodology, social partnership, identification, differential games.

\section{Introduction}

Social partnership problems in the continuous professional education system (CPE) is updated by the processes, both obvious and latent, which directly or indirectly contribute to the social strain growth in different life activity spheres of the modern Russian society.

Such processes produce a significant impact on the educational and professional activity. Inefficiency of the model of provision of the professional development conditions for the already working specialists in the existing professional education system increases. The measures to provide labor competitive ability and the worker's adaptation and mobility with account of the specifics of the regional labor market development, are obviously insufficient. Dissatisfaction with the existing system of professional training, re-training, and advanced training is demonstrated by both trainees studying in CPE structures and employers interested in effective educational programs (Tarasenko, 2009). As a result, the issue of an optimal CPE model development based both on the economic feasibility and on active cooperation and mutual trust of all educational process members, becomes quite acute. Such an approach to the CPE system organization suggests application of the social partnership principles and mechanisms as the methodological ground.

The scientific novelty of the research objective consists in the selected pattern and methods of the studies of the social partnership models in the CPE system. In particular, the following is suggested for the first time: an analytical and simulation study of the social partnership organization principles by means of dynamic theoretical game models; a study of the social partnership dynamics in the continuous professional education with account of the specific nature of the social and economic situation in the region, requirements, interests, and opportunities of all of CPE programs participants.

The main task is the research of the regularities and mechanisms of motivation formation and cooperation of the social partnership constituents in the continuous professional education sphere with the help of dynamic theoretical game models.

The article contains the description of the theoretical and methodological grounds of the inter-disciplinary research of the social partnership in the CPE system, based on the differential games simulation. 


\section{Theoretical and Methodological Analysis of Social Partnership in the CPE System}

Methodological issues of social partnership are studied in the works of a number of Russian scientists (Gusliakova et al., 2003; Podverbnykh, 2004; Remorenko, 2003), including the performed analysis of the social and historical aspect of the social partnership development in Russia (Burliaeva, 2010). Multiple researches demonstrate that under certain conditions, partnership with employing companies allows to settle a whole range of pedagogical issues of the professional education system, one of which is the task of professional adaptation of students (Korsunov et al., 2002).

Works of foreign authors at a due level research the place and role of social partnership in the education system (Keith, 2011; Siegel, 2010), the theoretical and applied researches of the scientific provision of the continuous and multilevel education system and cooperation with the social partners in the area of a demanded specialist training are emphasized (Anderson Arnold, 1966; Morel, 1998).

Foreign experience application in the Russian conditions is quite ambiguous due to social and cultural differences, but rational, objective mechanisms of social partnership must be detected and applied as far as reasonable. Works of many researchers make it possible to justify the strategic aims and objective pre-requisites of the social partnership formation in the personnel education and training.

Relying on the methodology of the social capital research by Bourdieu, the problem of social partnership in the continuous professional education system within the context of the study of the human potential investment-driven development was analyzed by Borisov (Bourdieu, 1993; Borisov, 1998).

Formation of social partnership in personnel training, talent pool forecasting has been researched to a less extent by science, no stages of social partnership formation on the regional level have been developed, and no research on the problems of institutionalization process in the social partnership has been performed.

The majority of works devoted to the social partnership problem do not describe the structural and substantial elements of social partnership, associated with the participants' strategic interests.

The social partnership problems in the continuous professional education system are considered in the number of works by domestic authors and studied from the point of view of their impact on the human personality formation and professional socialization of the youth (Tarasenko, 2009; Tarasenko, Nor-Averian, 2013; Manets, 2009). For example, Tarasenko researched conceptual frameworks of social partnership within the study of the social interaction mechanisms in the professional socialization sphere. The core principle of social partnership is the voluntariness of interaction of the constituents of the social partnership, the efficiency of which will be determined by the degree of trust/distrust between such constituents.

The study of domestic and foreign sources demonstrated a large variety of publications on the social partnership issue. However, their significant part is of descriptive or applied nature. They lack the sociological aspect of the partnership interactions consideration, and the narrow approach towards social partnership as a technology of social and labor relations settlement in organizations prevails. Most authors adhere to the traditional of social partnership as a tool for the labor relations conflictogenity reduction.

Foreign researchers mostly consider social partnership in respect of the relations between employees, employers, and professional unions. Social partnership relations are analyzed in the higher education system as well, where a significant role in their success is played by the consideration of social and cultural differences.

Far lesser publications are devoted to the mathematical modeling of social partnership. Talman and Yang (2011) suggest a general model of the partnership formation in a cooperative or competitive environment. Fandel et al. (2012) apply the Cobb-Douglas production function for measuring the synergistic effects in the public and private partnership project. An analysis of social partnership in the complex organizational network was performed by Wilson et al. (2010). Romanian researchers Diaconu and Pandelica studied partnership relations between business and academic organizations and their impact on the form of modern universities (Diaconu and Pandelica, 2012). Zaharatul et al. (2012) suggested a synergistic model of the intellectual three-sided partnership "Polytechnic university - industry - students" using Malaysia as an example.

To solve the objectives of analysis, forecasting, and control in the social partnership area, it seems reasonable to apply mathematic modeling. Along with that, the most suitable apparatus is provided by differential games (Zenkevich et al., 2009; Dockner et al., 2000), describing conflict interaction of aim-oriented constituents in the course of their joint impact on the controlled object's dynamics. In particular, differential gaming models allow to find compromise solutions for conflicts, research the challenges of the public and private interests' coordination, carry out a comparative analysis of the efficiency of different versions of the social partnership organization, detect conditions of dynamic stability of the social partnership relations.

The important methodological task of mathematic modeling in general and of the differential gaming simulation in 
particular is the identification of models. It is necessary to distinguish structural identification (selection of the classes of functions participating in the model construction) and numerical identification (determination of these functions' parameters). In respect of the sociological researches, identification is performed based on the opinion polls' data. Model identification is linked with the problem of the controlling impacts selection, which is in simple cases solved analytically, and in more complex cases-with the help of simulation modeling based on the scenarios method (Kelton and Lowe, 2004).

The problems of mathematic modeling of social processes are studied collectively by the sociologists and mathematicians of the Southern Federal University within the context of the study of social partnership in the CPE system and other social processes with the help of theoretical games simulation modeling (Diachenko et al., 2013; Sushchii et al., 2013; Tarasenko and Ugolnitskii, 2014; Diachenko et al., 2014). This work describes the opportunities of application of the differential games models of a special type for the analysis of social partnership relations in the CPE system and the methodological issues of such models identification with the use of the opinion polls' data. In particular, different methods of the social partnership organization are compared (isolation, hierarchy, cooperation) in terms of the public welfare, which is usually considered ultimate in the conditions of cooperation.

According to the authors, the main public purpose of social partnership is to provide a balance of implementation of interests of the main social constituents of the CPE system. As for the partnership relations in the CPE field, social partnership provides the balance of interests of all social groups involved in the collective activity, regardless of the social status, property status, resources, etc.

\section{Theoretical Games Model of Social Partnership in the CPE System}

The suggested model considers social partnership between three management subjects-a university professor $(\mathrm{P})$, an employer (E), and a student (S). Initially, it is suggested that the subjects have equal rights and take decisions simultaneously and independently. All management subjects aim at maximizing their award discounted with the coefficient $\rho$ at a certain period $T$. The differential game model of the combination of public and private interests is the following:

$$
\begin{aligned}
& J_{i}=\int_{0}^{T} e^{-\rho t}\left[g_{i}\left(r_{i}-u_{i}(t)\right)+s_{i}(t) c(x(t))\right] d t+e^{-\rho T} s_{i}(T) c(x(T)) \rightarrow \max , \\
& 0 \leq u_{i}(t) \leq r_{i}, \quad i \in N ; \\
& \dot{x}=h(x(t))+f\left(u_{B}(t), u_{P}(t), u_{C}(t)\right), x(0)=x_{0} .
\end{aligned}
$$

The model of interests combination (1) - (3) suggests that each constituent $i$ from the range $N=\{B, P, C\}$ distributes its budget $r_{i}$ between two sections: share $u_{i}(t)$ (player's management) is assigned for the increase of the students' professional training level, and the remaining part $r_{i}-u_{i}(t)$ is used for the private activity financing (for example, business development, securities acquisition, bank deposits formation or merely consumption). Accordingly, the current award of the player is comprised of the revenues from the private activity and usefulness from the students' (society's) professional training level.

In the general case, in the model (1) - (3): $g_{i}(z)$ is the concave increasing function of variable $z$, expressing subjects' incomes from private activity; ${ }^{x(t)}$ is the level of the students' professional training (the state variable); ${ }^{c(x)}$ is the concave increasing function providing financial expression of the social usefulness from the professional training level; $s_{i}(t)$ is the share of the $i$-th subject in such usefulness; $h$ is the decreasing function, i.e. if there are no investments, the level of proficiency decreases; $f$ is the increasing function of the subjects' investments into the students' professional training.

The simplified model version (1) - (3), initially applied in the researches, uses the linear function $c(x(t))=c x(t)$, where $c>0$ is the coefficient of transfer of the professional training level into the social usefulness, and the linear function $h(x(t))=a x(t), a<0$, which makes the model linear in terms of the state (Dockner et al., 2000). Further on, for the simplicity, the linear function $f\left(u_{B}(t), u_{P}(t), u_{C}(t)\right)=\sum_{i \in N} b_{i} u_{i}(t)$ is taken, where $b_{i}>0$ is the coefficient of contribution of investments of the ${ }^{i}$-th player into the increase of the students' proficiency, and the power function of income from private activity $g_{i}\left(r_{i}-u_{i}(t)\right)=k_{i}\left(r_{i}-u_{i}(t)\right)^{p_{i}}, k_{i}>0,0<p_{i}<1, i \in N$.

As for the state linear model (1) - (3), standard methods of differential games theory (Dockner et al., 2000) can 
help find the Nash equilibrium, which is deemed to be the game solution. Its appearance is omitted here. Let us remind that in the situation with the Nash Equilibrium, it is unfavorable for the players to deviate from the agreed strategy if all other players behave in the same manner.

The obtained analytical solution allows drawing qualitative conclusions regarding social partnership within the frames of hypothesis of the model (1) - (3). For example, the condition $\lambda_{i}(t) \geq k_{i} p_{i} r_{i}^{p_{i}-1} / b_{i}$ characterizes "pure selfishness" of player $i$, by virtue whereof the whole budget is spent only for private activity. It is to be noted that "pure collectivism" $\left(u_{i}(t)=r_{i}\right)$, when all funds are spent for the professional level improvement and social partnership development in the CPE system, is not achieved in the equilibrium strategy. From the equilibrium path's appearance, it is visible that maintaining a high level of proficiency under linear dynamics of the state is rather difficult, since the first additive element in the corresponding expression decreases exponentially.

Now, let us consider the cooperative setting of the task of social partnership management, in which all the subjects unite and jointly maximize the aggregate prize functionality

$$
J=\sum_{i \in N} J_{i}=\int_{0}^{T} e^{-\rho t}\left[\sum_{i \in N} k_{i}\left(r_{i}-u_{i}(t)\right)^{p_{i}}+c x(t)\right] d t+e^{-\rho T} c x(T)
$$

for all managements (2) due to the dynamic equation (3). In this case, we obtain a Pareto - optimal solution and the corresponding path, which are also obvious for the state linear model. Quantitative characteristic of the general system losses from non-cooperative behavior provide the value of the "anarchy price" (Algorithmic Game Theory, 2007)

$$
P A=\frac{\sum_{i \in N} J_{i}^{N E}}{J^{P O}} .
$$

In the expression (5) denominator, there is a value of the aggregate prize functionality (public welfare of the social partnership participants) at the cooperative behavior (maximum development of the social partnership), and in the numerator-at the independent selfish behavior of the players. In case $P A=1$, the social partnership system is ideally coordinated, otherwise the anarchy price deviation from 1 characterizes general system losses from the subjects' selfishness. In that case, the coordination can be improved by two methods: voluntary cooperation of the players (in case the level of the social and partnership relation level allows that), or introduction of hierarchic management (for example, by the government). Therefore, we will examine the hierarchic setting of the task of the social partnership management. Let the lower management level be presented by the subjects from range $N=\{B, P, C\}$ with the win functionality (1) and limitations (2) - (3), and the upper level be presented by the government maximizing the aggregate prize functionality (4). For the purpose of simplicity, let us consider that the governmental management is represented by the program (depending on the time only) strategies $s(\cdot)=\left(s_{B}(\cdot), s_{P}(\cdot), s_{C}(\cdot)\right)$ meeting the conditions of social usefulness distribution

$$
s(\cdot) \in S=\left\{s(t): s_{i}(t) \geq 0, \sum_{i \in N} s_{i}(t)=1, t \in[0, T]\right\} .
$$
regulation.

Then a hierarchic differential game of the type ${ }^{c_{c}}$ arises (Gorelik et al., 1991) with the following informative

1. The leading player (the government) chooses a program strategy of type (6) and informs other players in range $N=\{B, P, C\}$.

2. Being aware of the selected strategy (6), players from range $N=\{B, P, C\}$ play a differential game (1) - (3) between each other, the solution of which shall be a Nash equilibrium.

3. In fact, the leading player chooses strategy (6) in such a way as to maximize his prize (4) in the Nash equilibrium range.

More complex regulations of the hierarchic games are also possible, which account the dependence of the leading player's strategy on the subordinates' management and/or the game state (Gorelik et al., 1991). At hierarchic settings, it is also possible to calculate the value of the anarchy price, adding the players' prizes for the hierarchic game solution into the formula numerator.

Another important feature of the differential games' solutions is their dynamic stability (Dockner et al., 2000). Omitting details, we can describe this feature as follows. A solution is deemed dynamically stable, in case it remains optimal at any moment of the game scenario. That means that during the whole game, it is not favorable for the players to deviate from the solution discovered at the initial moment. In sociological terms, the achieved social partnership agreement remains valid for the whole period of its effectiveness. Therefore, it is obvious that only dynamically stable 
solutions have a common sense. It is known, for example, that the Nash equilibrium in a differential game is always dynamically stable, though hierarchic games' solutions do not usually possess such a feature, which requires application of special regularization procedures (Zenkevich et al., 2009).

For the purpose of construction of the above-stated theoretical game models of social partnership in the CPE system, the research team under guidance of Tarasenko developed social tools (questionnaires) for the social partnership study, allowing to detect the value-related and motivation characteristics of the educational activity subjects, monitor obligations undertaken by the aggregate partners in the CPE system, forecast their fulfillment and readiness of all the participants to contribute both in the form of non-material cooperation and in the form of financial investment into the CPE system development.

Concepts operationalization and the task of further transformation of the quantitative results obtained during an opinion poll into cooperative and dynamic models of the group control over the professional training quality in the CPE system, including their analytical and simulation research, determined the questionnaires' logical structure and types.

All questionnaire items can be grouped by the following indicators:

1. The respondents' general characteristics allowing to identify the groups of subjects - participants of CPE.

2. The characteristic of respondents' incomes with account of the values summarizing by the types of activity, as well as investments distribution for the purpose of the competitive ability improvement among the participating partners; allocation of the incomes' share spent for CPE.

3. Preparedness of all educational process subjects to make a material and non-material contribution into the CPE structures development.

4. Evaluation of the professional training efficiency in the CPE system.

5. Identification of the level of material and non-material prizes from the social partnership subjects' participation in the CPE.

At the questionnaire compilation, we used open questions with further transformation of the response items into a nominal scale; open questions with further transformation of the responses into an interval scale; open questions with further transformation of the response items into an ordinal scale.

\section{Conclusion}

The article describes methodological problems of the differential games modeling with regard to social partnership in the CPE system and identification of the models used. The suggested methodology allows the following:

- to find compromise solutions regarding social partnership subjects' interaction with account of the public and private interests coordination at investment resources distribution;

- to analyze features of the found solutions in the content-related terms of social partnership;

- to perform a comparative analysis of different methods of the social partnership organization (isolation, hierarchy, cooperation) and a qualitative analysis of their efficiency with the help of the anarchy price indicator;

- to detect the conditions of dynamic stability of the social partnership relations;

- to perform structural and numerical identification of the used models, including the use of special software, expert evaluations, and the scenario approach;

- to obtain solutions for different information regulations of differential games with the help of corresponding computer simulation scenarios.

In the future, it is planned to apply the specified methodology for the processing and analysis of materials of social polls performed in 2015 at the Southern Federal University and the Rostov State Medical University.

\section{Acknowledgements}

The article was prepared with the financial assistance of the Russian Foundation for Humanities, project No.14-03-00236.

\section{References}

Anderson Arnold, C. (1966). The Modernization of Education. Modernization: The Dynamics of Growth. New York, London: Basic Books Inc.

Bourdieu, P. (1993). Social space and the genesis of the classes. Sociology of Politics. Moscow: Logos [in Russian].

Burliaeva, V.A. (2010). The development of social partnership in Russia: social and historical aspect. Bulletin of the Adygeya State University. Series 1: Area Studies: philosophy, history, sociology, law, political science, cultural studies, 2 [in Russian]. 
Diachenko, V.K., Tarasenko, L.V., \& Ugolnitskii, G.A. (2013). Simulation of social partnership in system of additional vocational training. Managing large systems (Moscow: Institute of Control Sciences, Russian Academy of Sciences), 46, $179-196$ [in Russian].

Diachenko, V.K., Ugolnitskii, G.A., \& Tarasenko, L.V. (2014). Computer Simulation of Social Partnership in the System of Continuing Professional Education. Advances in Systems Science and Application, 14(4), 378-387 [in Russian].

Diaconu, M., \& Pandelica, A. (2012). The partnership relationship between economic academic and business environment, component of modern university marketing orientation. Procedia - Social and Behavioral Sciences, 62: 722-727.

Dockner, E., Jorgensen, S., Long, N.V., \& Sorger, G. (2000). Differential Games in Economics and Management Science. Cambridge University Press.

Fandel, G., Giese, A., \& Mohn, B. (2012). Measuring synergy effects of a Public Social Private Partnership (PSPP) project. Int. J. Production Economics, 140, 815-824.

Gorelik, V.A., Gorelov, M.A., \& Kononenko, A.F. (1991). Analysis of conflict management systems. Moscow: Radio and Communications [in Russian].

Gusliakova L.G., Mishin A.K., \& Tkachenko V.V. (2003). Social partnership: problems, realities and perspectives. Ministry of Education and others. Barnaul [in Russian].

Keith, N. (2011). Engaging in Social Partnerships: A Professional Guide for Successful Collaboration in Higher Education. Routledge.

Kelton, D.B., \& Lowe, A.M. (2004). Simulation. St. Petersburg: Peter [in Russian].

Korsunov, A.V., Litvinova, N.P., \& Safina, Z.N. (2002). Social Partnership in Adult Education. Ministry of Education of Russia. Tatar Institute of Business Assistance. Veliky Novgorod: TISBI [in Russian].

Manets, T.V. (2009). Social partnership in vocational education as an institutional arrangement (Doctor's thesis). Yekaterinburg [in Russian].

Podverbnykh, O.E. (2004). On the structure of social partnership. Vocational Education, 8: 30-31 [in Russian].

Remorenko, I.M. (2003). "Social Partnership" in education: the notion and the activities. The new city: the formation to change the quality of life. Moscow; St Petersburg: Yugorsk [in Russian].

Siegel, D. (2010). Organizing for Social Partnerships: Higher Education in Cross-Sector Collaboration. Routledge.

Smirnov, I.P. (2003). Formation of the mechanism of social partnership. Vocational Education, 2, 30-31 [in Russian].

Sushchii, S.Y., Ugolnitskii G.A., \& Diachenko V.K. (2013). Simulation fight against extremism in the North Caucasus. Sociology, 4M, 37, 126-150 [in Russian].

Talman, D., \& Yang, Z. (2011). A model of partnership formation. Journal of Mathematical Economics, 47, $206-212$.

Tarasenko, L.V. (2009). Additional professional education: the establishment of the Institute of secondary professional socialization. Rostov-on-Don: Southern Federal University Press [in Russian].

Tarasenko, L.V., \& Nor-Arevian, O.A. (2013). Specifics of professional socialization of modern Russian students (for example, universities of Rostov region). Azov: AzovPress [in Russian].

Tarasenko, L.V., \& Ugolnitskii, G.A. (2014). Modeling of social partnership in system of additional vocational training: research methodology. Engineering Vestnik of Don, 3. Retrieved from: URL: http://ivdon.ru/ru/magazine/archive/n3y2014/2473 [in Russian].

Ugolnitskii, G.A. (1999). Social position and the distribution of power. Sociology, 4M, 11, 161-178 [in Russian].

Ugolnitskii G.A. (2000). Models of social hierarchy. Moscow: High school book [in Russian].

Nisan, N., Roughgarden, T., Tardos, E., \& Vazirani, V. (Eds.). (2007). Algorithmic Game Theory. Cambridge University Press.

Wilson, E.J., Bunn, M.D., \& Savage, G.T. (2010). Anatomy of a social partnership: A stakeholder perspective. Industrial Marketing Management, 39, 76-90.

Zaharatul, A.A.Z., Abd Shukor, H., \& Ghazari, A.A. (2012). Smart tri-partite partnership: polytechnic - industry - student. Procedia Social and Behavioral Sciences, 31, 517-521.

Zenkevich, N.A., Petrosian, L.A., \& Young, D.V.K. (2009). Dynamic Games and their application in management. St. Petersburg: Graduate School of Management [in Russian]. 